\title{
PENGARUH VITAMIN B DAN BENZILADENIN TERHADAP PERTUMBUHAN BIBIT ANGGREK PHALAENOPSIS HASIL KULTUR JARINGAN
}

\author{
Sukartini, Sri Ramadiana \& Dwi Hapsoro \\ Jurusan Agroteknologi, Fakultas Pertanian Universitas Lampung \\ Jl. Prof. Dr. Soemantri Brodjonegoro no. 1 Bandar Lampung 35145 \\ Email: titin_sukartini92@yahoo.co.id
}

\begin{abstract}
ABSTRAK
Anggrek dinilai sebagai salah satu bunga yang indah. Minat terhadap pertumbuhan anggrek cenderung meningkat di kalangan masyarakat Indonesia baru-baru ini. Salah satu genus yang populer di keluarga anggrek adalah Phalaenopsis. Hampir semua anggrek tumbuh lambat, termasuk Phalaenopsis, beberapa perawatan tertentu harus diterapkan untuk meningkatkan pertumbuhannya. Penelitian ini bertujuan untuk menyelidiki pengaruh konsenterasi dari vitamin B dan benziladenin (BA) terhadap pertumbuhan Phalaenopsis. Penelitian dilakukan dengan rancangan acak lengkap dengan tiga ulangan. Perlakuan diatur secara faktorial yang terdiri dari vitamin B $\left(0\right.$ dan $\left.1 \mathrm{~g} \mathrm{l}^{-1}\right)$ dan konsentrasi BA $\left(20\right.$, 40, dan $\left.60 \mathrm{mg} \mathrm{l}^{-1}\right)$. Hasil penelitian menunjukkan bahwa aplikasi vitamin B mengakibatkan peningkatan pertumbuhan sedangkan peningkatan konsentrasi BA menyebabkan penurunan pertumbuhan seperti yang ditunjukkan oleh berat tanaman segar, jumlah daun, dan jumlah akar. Perlakuan tersebut tidak mempengaruhi jumlah tunas baru. Kedua faktor menunjukkan pengaruh interaksi diantara keduanya, di mana peningkatan pertumbuhan akibat pengaruh vitamin B bergantung pada konsentrasi BA. Hasil penelitian menunjukkan bahwa kombinasi dari $1 \mathrm{~g} \mathrm{l}^{-1}$ vitamin $\mathrm{B}$ dan $20 \mathrm{mg} \mathrm{l}^{-1} \mathrm{BA}$ merupakan perlakuan terbaik dalam meningkatkan pertumbuhan tanaman anggrek.
\end{abstract}

Kata kunci : Anggrek, benzyladenine, Phalaenopsis, vitamin B.

\section{PENDAHULUAN}

Anggrek memiliki warna bunga yang beragam, bentuk dan ukuran yang unik serta vase life yang panjang. Oleh sebab itu, anggrek banyak diminati oleh konsumen baik dari dalam maupun luar negeri. Salah satu jenis anggrek yang paling banyak digemari dan dikembangkan adalah anggrek Phalaenopsis. Menurut The American Orchid Society, genus Phalaenopsis mengambil porsi $75 \%$ dari seluruh pasar anggrek dunia (Griesbach, 2002).

Anggrek Phalaenopsis, dan secara umum spesies dalam famili Orchidaceae, menunjukkan pertumbuhan vegetatif yang lambat. Oleh karena itu perlakuan khusus seperti pemupukan dan pemberian lingkungan tumbuh yang optimal diharapkan dapat mendorong pertumbuhan dan produktivitas tanaman anggrek. Selain pemupukan, pemberian vitamin B dilaporkan dapat mendorong pertumbuhan anggrek (Surtinah dan Mutryarny, 2013). Pertumbuhan akar dapat dirangsang dengan penambahan vitamin yang berperan untuk mempercepat pembelahan sel meristem akar (Limarni et al., 2008).
Pemberian pupuk Grow Quick LB, yang mengandung vitamin B1, dilaporkan dapat mendorong pertumbuhan anggrek Dendrobium pada stadia kompot (community pot) (Surtinah dan Mutryarny, 2013).

Pemberian zat pengatur tumbuh benziladenin (BA) juga dilaporkan dapat memacu pertumbuhan anggrek (Wati, 2009; Handayani, 2011; Alicia, 2011). BA adalah zat pengatur tumbuh sitokinin. Peranan sitokinin dalam tanaman adalah mengatur pembelahan sel, pembentukan organ, pembesaran sel dan organ, pencegahan kerusakan klorofil, pembentukan kloroplas, penundaan senesens, pembukaan dan penutupan stomata, serta perkembangan mata tunas dan pucuk (Harjadi, 2009). Hasil penelitian Handayani (2011) menunjukkan bahwa pemberian $20 \mathrm{mg} \mathrm{l}^{-1} \mathrm{BA}$ pada planlet anggrek Phalaenopsis dapat mendorong pertumbuhan planlet. Pemberian larutan BA pada bibit Phalaenopsis amabilis mulai dari umur satu bulan hingga empat bulan sejak dikeluarkan dari botol juga dilaporkan dapat memacu pertumbuhan (Yusnita, 2014). Oleh karena itu, pemberian vitamin B dan BA diharapkan dapat meningkatkan pertumbuhan anggrek Phalaenopsis. 
Penelitian ini bertujuan untuk mengetahui pengaruh pemberian vitamin B terhadap pertumbuhan anggrek Phalaenosis, mengetahui pengaruh peningkatan konsentrasi benziladenin (BA) terhadap pertumbuhan anggrek Phalaenopsis, dan mengetahui apakah terdapat interaksi antara pemberian vitamin B dan peningkatan konsentrasi benziladenin (BA) terhadap pertumbuhan anggrek Phalaenopsis.

\section{BAHAN DAN METODE}

Bahan yang digunakan dalam penelitian ini adalah bibit anggrek Phalaenopsis hasil kultur jaringan yang telah diaklimatisasi selama enambulan. Sebelum aklimatisasi, terlebih dahulu disiapkan media aklimatisasi, yang berupa cacahan pakis dan sabut kelapa (Gambar 1). Sebelum digunakan, cacahan pakis dan sabut kelapa direndam dalam $2 \mathrm{~g} \mathrm{l}^{-1}$ Dithane M-45 80 WP selama satu malam, lalu dikering-anginkan.

Botol yang berisi bibit anggrek anggrek berukuran kecil (planlet anggrek) diisi dengan sedikit air, lalu dikocok-kocok untuk melepaskan media agar-agar dari botol. Bibit dikeluarkan dari botol dengan pinset secara hati-hati agar tidak merusak akar dan daunnya, lalu dimasukkan ke dalam ember berisi air untuk dibersihkan dari sisa-sisa media agar, lalu dicuci lagi dengan menggunakan air mengalir hingga bibit benar-benar bersih. Setelah itu, bibit dipilih yang memiliki ukuran hampir sama untuk dijadikan bahan eksperimen.

Bibit direndam selama 10 menit dalam larutan 1 $\mathrm{g} \mathrm{l}^{-1}$ Dithane M-45 $80 \mathrm{WP}$, lalu dikeringanginkan di atas kertas koran. Penanaman dilakukan dengan cara melilit longgar bibit anggrek menggunakan sabut kelapa kemudian disusun di dalam pot yang berisi potongan styrofoam dan cacahan pakis (10 tanaman per pot) (Gambar 1). Tanaman kemudian diletakkan di atas bench yang dinaungi paranet dalam rumah kaca. Penyiraman tanaman dilakukan dengan cara pengabutan menggunakan sprayer. Pemupukan dengan pupuk GrowMore (32:10:10) dilakukan seminggu sekali menggunakan sprayer dengan dosis $1 \mathrm{~g} \mathrm{l}^{-1}$. Setelah 6 bulan diaklimatisasi, bibit anggrek dipindahtanam secara individu pada pot plastik berdiameter $10 \mathrm{~cm}$ yang berisi media potongan styrofoam dan cacahan pakis dan siap untuk diperlakukan (Gambar 1).

Vitamin B dilarutkan dalam air sehingga konsentrasinya $1 \mathrm{~g} \mathrm{l}^{-1}$. Benziladenin (BA) dilarutkan dalam air menjadi beberapa konsentrasi yaitu 20, 40, dan $60 \mathrm{mg} \mathrm{l}^{-1}$. Setiap minggu bibit anggrek disemprot dengan larutan vitamin B dan BA sesuai dengan

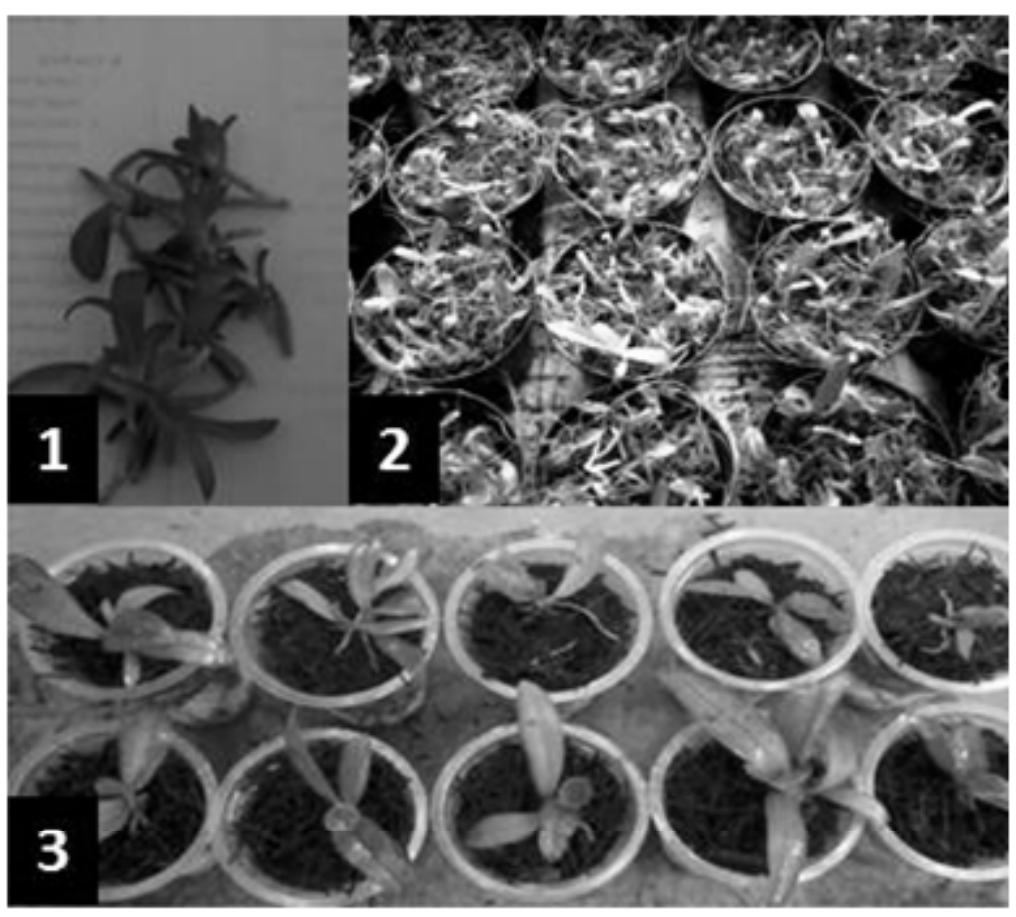

Gambar 1. (1) Bahan tanaman anggrek Phalaenopsis hasil kultur jaringan. (2) Bibit anggrek diaklimatisasi pada media aklimatisasi yang terdiri dari sabut kelapa dan cacahan pakis. Bibit diikat longgar dengan sabut kelapa lalu dimasukkan ke dalam pakis. (3) Setelah 6 bulan diaklimatisasi, bibit anggrek ditanam pada media pakis dalam pot plastik air mineral (diemeter $10 \mathrm{~cm}$ ) untuk diperlakukan. 
perlakuan menggunakan hand sprayer. Kandungan vitamin $\mathrm{B}$ yang digunakan per tablet $(1 \mathrm{~g}$ per tablet) adalah $2 \mathrm{mg}$ vitamin $\mathrm{B}_{1}, 2 \mathrm{mg}$ vitamin $\mathrm{B}_{2}, 2 \mathrm{mg}$ vitamin $\mathrm{B}_{6}, 2 \mathrm{mg}$ vitamin $\mathrm{B}_{12}, 10 \mathrm{mg}$ kalsium pantotenat, dan $20 \mathrm{mg}$ nicotinamidum. Berdasarkan kalibrasi, setiap tanaman mendapatkan masing-masing $8 \mathrm{ml}$ larutan BA dan $8 \mathrm{ml}$ larutan vitamin B setiap kali perlakuan. Aplikasi perlakuan dilakukan pada sore hari pukul $16.00-17.00$ WIB. Sebelum ditanam setiap bibit ditimbang untuk medapatkan data bobot basah awal dan pada akhir percobaan ditimbang lagi untuk mendapatkan data bobot basah akhir. Pengukuran di awal dan akhir percobaan juga dilakukan untuk jumlah daun, jumlah akar, dan jumlah tunas baru.

Penelitian dilaksanakan di rumah kaca Fakultas Pertanian Universitas Lampung dari bulan MaretSeptember 2013. Penelitian ini dilakukan dengan rancangan acak lengkap dengan perlakuan yang disusun secara faktorial. Faktor pertama adalah vitamin B yaitu tanpa dan dengan penyemprotan $1 \mathrm{gl}^{-1}$ vitamin $\mathrm{B}$. Faktor kedua adalah tiga konsentrasi BA $(20,40$, dan 60 $\mathrm{mg}^{\mathrm{l}^{-1}}$ ). Setiap kombinasi perlakuan diulang $3 \mathrm{kali}$ dan masing-masing ulangan terdiri dari 10 tanaman. Homogenitas ragam antarperlakuan diuji dengan uji
Barlett. Bila kedua asumsi terpenuhi, maka analisis data dilanjutkan dengan analysis of variance (Anova). Pemisahan nilai tengah dilakukan dengan uji beda nyata terkecil (BNT) pada taraf $5 \%$. Veriabel yang diamati adalah kenaikan bobot basah tanaman, kenaikan jumlah daun, kenaikan jumlah akar, dan kenaikan jumlah tunas baru.

\section{HASIL DAN PEMBAHASAN}

Pemberian vitamin B dapat meningkatkan pertumbuhan bibit tanaman anggrek Phalaenopsis yang ditunjukkan oleh kenaikan bobot basah tanaman (Tabel 1). Hal ini terjadi pada tanaman yang diberi $20 \mathrm{mg} \mathrm{l}^{-1}$ BA dan $60 \mathrm{mg} \mathrm{l}^{-1}$ BA. Pada tanaman yang diberi 40 $\mathrm{mg}^{-1} \mathrm{BA}$, pemberian vitamin $\mathrm{B}$ tidak mempengaruhi pertumbuhan (Tabel 1). Hal ini menunjukkan adanya pengaruh interaksi (Tabel 1) antara pemberian vitamin $\mathrm{B}$ dan peningkatan konsentrasi BA, bahwa pengaruh vitamin tergantung pada berapa konsentrasi BA yang diberikan kepada tanaman anggrek. Peningkatan konsentrasi BA dari $20 \mathrm{sd} 60 \mathrm{mg} \mathrm{l}^{-1}$ secara umum menyebabkan penurunan pertumbuhan tanaman yang ditunjukkan oleh penurunan bobot basah tanaman (Tabel

Tabel 1. Respons bibit anggrek Phalaenopsis hasil kultur jaringan terhadap kombinasi vitamin B dan konsentrasi benziladenin (BA) setelah 6 bulan pada media pakis.

\begin{tabular}{|c|c|c|c|c|c|c|c|c|c|c|c|c|}
\hline \multirow{2}{*}{ Perlakuan } & \multicolumn{3}{|c|}{ Bobot Tanaman } & \multicolumn{3}{|c|}{ Jumlah Daun } & \multicolumn{3}{|c|}{ Jumlah Akar } & \multicolumn{3}{|c|}{ Jumlah Tunas Baru } \\
\hline & Akhir & Awal & Kenaikan & Akhir & Awal & Kenaikan & Akhir & Awal & Kenaikan & Akhir & Awal & Kenaikan \\
\hline \multicolumn{13}{|l|}{ Tanpa vitamin B } \\
\hline $20 \mathrm{mg} / 1 \mathrm{BA}$ & 3.66 & 1.64 & $2.02 b$ & 6.20 & 4.93 & $1.27 \mathrm{~b}$ & 7.27 & 5.73 & $1.54 \mathrm{~b}$ & 1.17 & 0.00 & 1.17 \\
\hline $40 \mathrm{mg} / 1 \mathrm{BA}$ & 2.97 & 1.63 & $1.34 \mathrm{c}$ & 6.60 & 5.80 & $0.80 \mathrm{c}$ & 7.40 & 6.33 & $1.07 \mathrm{c}$ & 150 & 0.00 & 1.50 \\
\hline $60 \mathrm{mg} / 1 \mathrm{BA}$ & 1.94 & 1.48 & $0.46 \mathrm{~d}$ & 5.73 & 5.20 & $0.53 \mathrm{~d}$ & 6.07 & 5.13 & $0.94 \mathrm{c}$ & 1.33 & 0.00 & 1.33 \\
\hline \multicolumn{13}{|l|}{ Dengan $1 \mathrm{~g} / \mathrm{l}$} \\
\hline \multicolumn{13}{|l|}{ vitamin $B$} \\
\hline $20 \mathrm{mg} / 1 \mathrm{BA}$ & 3.97 & 1.59 & 2.38 a & 6.73 & 5.27 & $1.46 a$ & 8.47 & 5.60 & $2.87 a$ & 0.83 & 0.00 & 0.83 \\
\hline $40 \mathrm{mg} / 1 \mathrm{BA}$ & 2.70 & 1.44 & $1.26 \mathrm{c}$ & 6.80 & 5.40 & $1.40 \mathrm{ab}$ & 6.67 & 5.73 & $0.94 \mathrm{c}$ & 1.40 & 0.00 & 1.40 \\
\hline $60 \mathrm{mg} / \mathrm{BA}$ & 3.39 & 1.54 & $1.85 \mathrm{~b}$ & 7.33 & 5.87 & $1.46 a$ & 7.07 & 6.20 & $0.87 \mathrm{c}$ & 1.83 & 0.00 & 1.83 \\
\hline
\end{tabular}

Signifikansi berdasarkan ANOVA (analysis of variance)

$\begin{array}{llll}\begin{array}{l}\text { Pengaruh utama: } \\ \text { Vitamin B }\end{array} & * & * & \text { tn } \\ \text { Konsentrasi BA } & * & * & \text { tn } \\ \text { Interaksi } & * & * & \text { tn }\end{array}$

Keterangan : Angka yang diikuti oleh huruf yang sama pada suatu kolom tidak berbeda nyata berdasarkan uji BNT pada $\mathrm{P} \leq 0,05, *=$ berbeda nyata berdasarkan Anova pada $\mathrm{P} \leq 0,05$, tn $=$ tidak berbeda nyata berdasarkan Anova pada $\mathrm{P} \leq 0,05$. 
1). Hal itu terjadi baik pada bibit yang diberi vitamin $B$ maupun yang tidak.

Pengaruh vitamin B yang dapat meningkatkan pertumbuhan juga tercermin pada pengaruhnya terhadap jumlah daun. Tabel 1 menunjukkan bahwa pemberian vitamin B menyebabkan kenaikan secara signifikan jumlah daun pada ketiga konsentrasi BA yang diaplikasikan. Pengaruh peningkatan konsentrasi BA antara 20-60 $\mathrm{mg} \mathrm{l}^{-1}$ terhadap jumlah daun bergantung pada diberi atau tidaknya vitamin B. Hal ini menunjukkan bahwa kedua faktor tersebut berinteraksi dalam mempengaruhi jumlah daun. Jika tidak diberi vitamin B, peningkatan konsentrasi BA dari 20-40 $\mathrm{mg} \mathrm{l}^{-1}$ menyebabkan peningkatan jumlah daun secara nyata, lalu menurun jika konsentrasi BA ditingkatkan menjadi $60 \mathrm{mg} \mathrm{l}^{-1}$. Akan tetapi, jika diberi vitamin B, peningkatan konsentrasi BA tidak berpengaruh secara signifikan terhadap jumlah daun.

Tabel 1 menunjukkan bahwa pemberian vitamin $B$ dapat meningkatkan jumlah akar. Hal ini terjadi pada tanaman yang diberi $20 \mathrm{mg} \mathrm{l}^{-1} \mathrm{BA}$. Tetapi pada tanaman yang diberi 40 dan $60 \mathrm{mg} \mathrm{l}^{-1} \mathrm{BA}$, pemberian vitamin B tidak berpengaruh terhadap jumlah akar. Dengan atau tanpa vitamin B, peningkatan konsentrasi BA menyebabkan penurunan jumlah akar. Pengaruh pemberian vitamin terhadap jumlah akar tergantung pada berapa konsentrasi BA yang diberikan (Tabel 1), yang merupakan cerminan adanya interaksi antara perlakuan vitamin dan konsentrasi BA dalam mempengaruhi jumlah akar.

Vitamin B dan peningkatan konsentrasi BA tidak berpengaruh nyata terhadap jumlah tunas baru yang dihasilkan (Tabel 1). Dari Tabel 1 tampak bahwa jumlah tunas baru yang dihasilkan adalah antara 1-2 tunas per tanaman. Penampakan tunas baru yang dihasilkan dapat dilihat pada Gambar 2.

Dari hasil yang dipaparkan di atas dapat dikemukakan bahwa efek vitamin B yang menyebabkan peningkatan bobot basah tanaman dan efek kenaikan konsentrasi BA yang menyebabkan penurunan bobot basah tanaman adalah melalui efek perlakuan tersebut terhadap jumlah daun dan jumlah akar. Hal ini terlihat dari hasil analisis statistik yang menunjukkan bahwa terhadap jumlah daun dan jumlah akar vitamin B berpengaruh nyata yaitu menyebabkan peningkatan jumlah daun dan jumlah akar. Dengan perkataan lain, kenaikan bobot basah tanaman disumbang oleh kenaikan jumlah daun dan jumlah akar, bukan oleh pembentukan tunas baru sebab vitamin B tidak berpengaruh nyata terhadap jumlah tunas baru. Hal yang sama juga dapat dikemukakan untuk pengaruh konsentrasi BA, yaitu bahwa pengaruhnya yang menyebabkan penurunan bobot tanaman juga disumbang oleh pengaruhnya yang menyebabkan penurunan jumlah daun dan jumlah akar, bukan oleh jumlah tunas baru.

Fenomena bahwa vitamin B menyebabkan peningkatan bobot basah tanaman, jumlah daun, dan jumah akar tetapi tidak nyata terhadap jumah tunas mengindikasikan bahwa mungkin vitamin B lebih banyak memainkan peran fisiologi yang hanya mendorong pertumbuhan. Pembentukan tunas baru bukan hanya merupakan fenomena pertumbuhan, tetapi juga merupakan suatu proses yang melibatkan pemrograman ulang aktivitas molekuler dan seluler yang bermuara pada diferensiasi. Pada umumnya, pemeran utama pemrograman seperti itu adalah zat pengatur tumbuh. Pada percobaan ini hampir semua tanaman
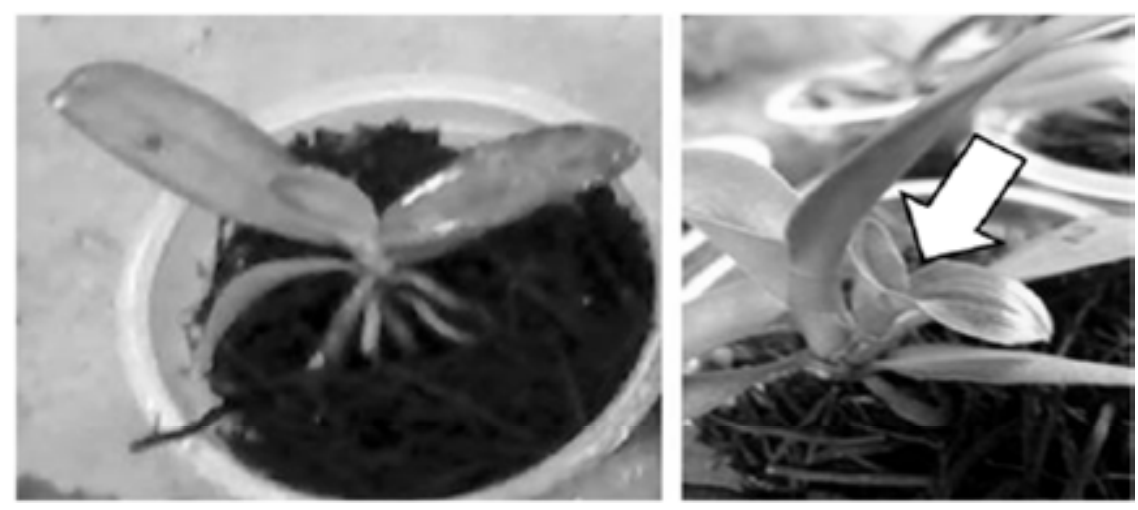

Gambar 2. Representasi bibit anggrek Phalaenopsis pada awal percobaan (kiri) dan akhir percobaan (kanan) yaitu setelah 6 bulan dipelihara pada media pakis dan diperlakukan dengan vitamin B dan benziladenin (BA). Tampak bahwa pada akhir percobaan muncul tunas baru (tanda panah). 
menghasilkan tunas baru (Gambar 2), padahal anggrek Phalaenopsis secara alami merupakan anggrek monopodial. Hal ini kemungkinan akibat peran BA dalam merangsang pembentukan tunas. Pada percobaan kami yang lain (data tidak ditampilkan) bibit anggrek Phalaenopsis yang tidak diberi BA semuanya tidak menghasilkan tunas baru; semunya menunjukkan pola pertumbuhan monopodial.

Pada percobaan ini peningkatan konsentrasi BA mengakibatkan penurunan pertumbuhan. Kemungkinan hal ini disebabkan oleh konsentrasi BA yang menjadi terlalu tinggi. Hasil percobaan peneliti lain pada tanaman anggrek Phalaenopsis menunjukkan bahwa pemberian BA pada konsentrasi $20 \mathrm{mg}^{-1}$ dapat memacu pertumbuhan (Handayani, 2011). Alicia (2011) menggunakan konsentrasi yang lebih rendah yaitu 10 mg $1^{-1}$ BA untuk memacu pertumbuhan anggrek Dendrobium. Memang pada umumnya pola efek konsentrasi BA adalah pada awalnya menyebabkan peningkatan pertumbuhan lalu pertumbuhan menurun seiring dengan kenaikan konsentrasi BA (Hapsoro et al., 2012; Yusnita et al., 2013; Palee et al., 2013).

Hasil percobaan ini menunjukkan bahwa pemberian $1 \mathrm{~g} \mathrm{l}^{-1}$ vitamin $\mathrm{B}$ memberikan hasil yang lebih baik jika dibandingkan tanpa vitamin B. Pemberian 1 $\mathrm{g}^{1^{-1}}$ vitamin $\mathrm{B}$ mampu meningkatkan jumlah daun tanaman sebesar 1,47 helai. Pemberian BA $20 \mathrm{mg} \mathrm{l}^{-1}$ yang dikombinasikan dengan $1 \mathrm{~g} \mathrm{l}^{-1}$ vitamin $\mathrm{B}$ memberikan hasil terbaik untuk variabel penambahan jumlah akar yaitu sebesar 2,87 dan bobot tanaman sebesar 2,39 g. Pemberian $1 \mathrm{~g} \mathrm{l}^{-1}$ vitamin B setiap seminggu sekali pada tanaman anggrek Phalaenopsis dapat meningkatkkan pertumbuhan tanaman. Selain itu, didukung dengan pemberian BA yang berfungsi merangsang pembelahan sel pada tanaman. Peningkatan bobot tanaman yang baik serta didukung dengan meningkatnya jumlah daun dan jumlah akar tanaman menunjukkan bahwa tanaman anggrek tumbuh secara optimal. Jika keadaan ini berlangsung secara terus menerus, maka diharapkan tanaman dapat menghasilkan bunga dengan kualitas yang baik.

\section{KESIMPULAN}

Hasil percobaan menunjukkan bahwa pemberian $1 \mathrm{~g} \mathrm{l}^{-1}$ vitamin $\mathrm{B}$ dapat mendorong pertumbuhan bibit anggrek Phalaenopsis yang ditunjukkan oleh peningkatan bobot basah tanaman, jumlah daun, dan jumlah akar, sedangkan peningkatan konsentrasi benziladenin dari 20-60 $\mathrm{mg} \mathrm{l}^{-1}$ menyebabkan penurunan pertumbuhan.

\section{DAFTAR PUSTAKA}

Alicia, J. 2011. Pengaruh Jenis Pupuk Daun dan Frekuensi Pemberian Benziladenin terhadap Pembesaran Seedling Anggrek Dendrobium Hibrida. (Skripsi). Fakultas Pertanian. Universitas Lampung. $49 \mathrm{hlm}$.

Griesbach, R.J. 2002. Development of Phalaenopsis orchids for the mass-market. p. 458-465. In: J. Janick and A. Whipkey (eds.), Trends in New Crops and New Uses. ASHS Press, Alexandria, VA.

Handayani, Y. 2011. Persilangan Dialel Lengkap Dua Tetua Anggrek, Pengecambahan Biji dan Pembesaran Seedling In Vitro serta Aklimatisasi Planlet Phalaenopsis. (Tesis). Pascasarjana Magister Agronomi. Universitas Lampung. 82 hlm.

Hapsoro, D., A.P. Febrianie, and Yusnita. 2012. In vitro shoot formation on sugarcane (Saccharum officinarum L.) callus as affected by benzyladenine concentrations. J. Agron. Indonesia. 40 (1): 56 - 61.

Harjadi, S. S. 2009. Zat Pengatur Tumbuh. Penebar Swadaya. Jakarta. $76 \mathrm{hlm}$.

Limarni, L., N. Akhir, I. Suliansyah, dan A. Riyadi. 2008. Pertumbuhan bibit anggrek (Dendrobium sp.) dalam kompot pada beberapa jenis media tanam dan konsentrasi vitamin $\mathrm{B}_{1}$. Jurnal Jerami. 1(1): $38-45$.

Palee, J., S. Dheeranupattana, A. Jatisatienr, and S. Wangkarn. 2013. Effects of BA and NAA on micropropagation and Stemona Alkaloids production of Stemona curtisii Hook. f. Chiang Mai J. Sci. 40(3) : $356-363$

Surtinah dan E. Mutryarny. 2013. Frekuensi pemberian Grow Quick LB terhadap pertumbuhan bibit anggrek Dendrobium pada stadia komunitas Pot. Jurnal Ilmiah Pertanian. 10 (2) : 31 - 40.

Wati, I. 2009. Pengaruh Jenis Pupuk, Frekuensi Pemupukan, Vitamin $\mathrm{B}_{1}$, dan Benziladenin (BA) pada Aklimatisasi dan Pembesaran Bibit Anggrek Dendrobium. (Skripsi). Fakultas Pertanian. Universitas Lampung. $57 \mathrm{hlm}$.

Yusnita, T. Wahyuningsih, P. Sulistiana, dan D. Hapsoro. 2013. Perbanyakan in vitro Sansevieria trifasciata 'Lorentii': regenerasi tunas, 
pengakaran, dan aklimatisasi planlet. J. Agron. Indonesia. 41(1): 70 - 76.

Yusnita. 2014. Perbanyakan In Vitro Tanaman Anggrek. Universitas Lampung. Lampung. 132 hlm. 